\title{
Delinking Indicators on Transport Output and Carbon Emissions in Xinjiang, China
}

\author{
Jie-fang Dong ${ }^{1,2,3}$, Jie-yu Huang ${ }^{1 *}$, Rong-wei Wu ${ }^{2,3}$, Chun Deng ${ }^{1}$ \\ ${ }^{1}$ Department of Economics and Management, Yuncheng University, \\ Yuncheng 044000, China \\ ${ }^{2}$ State Key Laboratory of Desert and Oasis Ecology, \\ Xinjiang Institute of Ecology and Geography, \\ Chinese Academy of Sciences, Urumqi 830011, China \\ ${ }^{3}$ College of Resources and Environment, \\ University of Chinese Academy of Sciences, \\ Beijing 100049, China
}

Received: 21 October 2016

Accepted: 5 December 2016

\begin{abstract}
This paper identifies the driving forces of $\mathrm{CO}_{2}$ emissions from 1990 to 2014 in Xinjiang's transport sector based on the logarithmic mean divisia index (LMDI) method. Then we introduce the decoupling index to further quantitatively analyze the delinking indicators on the transport sector's growth and environmental pressures. The results indicate that:

1) $\mathrm{CO}_{2}$ emissions increased significantly with an average annual growth rate of $8.7 \%$. On the contrary, energy intensity has declined constantly over the study period.

2) Economic growth, population size, industrial structure, internal structural and energy mix have proven to contribute to $\mathrm{CO}_{2}$ emissions increases. Moreover, economic growth plays a critical role in the increment with a contribution of 13.23 million tons, followed by population size and internal structure.

3) Xinjiang's transport witnessed a fluctuating decoupling progress with weak decoupling as the theme. In particular, the decoupling state moved from weak decoupling in 1991-2000 with short-term volatility to weak decoupling in 2001-2010. However, the coupling relationship was strengthened during 2011-2014.

4) Energy intensity is the most important factor for explaining the dissociation in Xinjiang's transport sector. However, internal structural, industrial structure, and population size has turned out to be the obstacles in decoupling progress.
\end{abstract}

Keywords: transport carbon emissions, decoupling index, LMDI, Xinjiang

*e-mail: hjy328@126.com 


\section{Introduction}

Global warming is one of the serious challenges for the sustainable development of human beings. The $\mathrm{CO}_{2}$ emissions generated by human activities constitute one of the most significant contributing factors to global warming [1]. According to the World Energy Outlook 2014 report of the IEA, transport has produced the second largest amount of $\mathrm{CO}_{2}$ emissions among all sectors around the world in 2012 [2]. Therefore, low carbon transport is of great significance to global carbon reduction.

With China's rapid economic development, its transport sector has experienced dramatic growth, leading to a large amount of related $\mathrm{CO}_{2}$ emissions $[3,4]$. Moreover, due to the lower energy efficiency, environmental problems in developing regions of developing countries are usually more severe [3, 5, 6]. For instance, Xinjiang Uygur Autonomous region, the biggest province in China (Fig. 1 ), has surging energy consumption demands and carbon emissions in the transport sector [7]. In 2013 the "One Belt, One Road" initiative was put forward by China's government [8-9]. By virtue of its unique geographic location, Xinjiang's transport sector will undoubtedly see rapid development after the implementation of this initiative [10-13]. Accordingly, there will be even more carbon emissions from the transport sector. Alongside the rapid growth of energy-related $\mathrm{CO}_{2}$ emissions in the transport sector is huge environmental pressure as well as other potential risks on Xinjiang [14-16]. In this condition, it is urgent that we analyze the driving factors of carbon emissions for green development of transport in Xinjiang. Furthermore, examining the relationship between economic growth and environmental pressure of the transport sector will also provide important policy implications for low-carbon transportation.

Academically, there are several studies interested in transportation energy conservation and emissions reduction measures as well as the links between

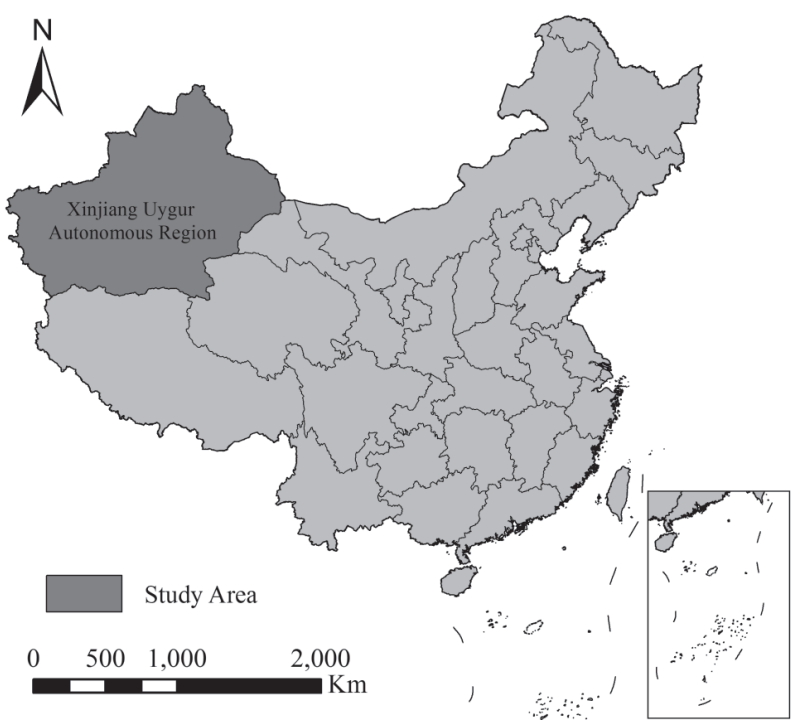

Fig. 1. Study area. transportation and other socioeconomic activities [17-28]. With increasing emissions from the transport sector and rising environmental awareness, $\mathrm{CO}_{2}$ emissions mitigation has attracted more attention in China [15, 17, 21, 29-33]. Researchers have analyzed the carbon emissions of the transport sector from various perspectives. For instance, Liu et al. [34] divided China's transportation sector into four segments, namely highway, waterway, airway, and railway, and investigated their carbon emissions separately. With regard to the research methods, two approaches are widely used at present. They are the index decomposition analysis (IDA) [12-13, 35-39] and the econometric method $[5,10,12,16,40-42]$. Compared with the econometric method, the IDA method has some advantages, namely theoretical foundation, adaptability, ease of use, and interpretation of results [43-45]. Therefore, since the 1980s, literature on decomposition based on the IDA method has been extremely prolific in various countries and regions, including Denmark [46], Italy [47], Brazil [48], and OECD countries [49].

Though the driving factors of $\mathrm{CO}_{2}$ emissions in the transport sector have been discussed extensively, there are two main shortcomings. Firstly, most of these studies focus on the national macroscopic level, and research on typical microscopic regions is rare. Due to China's imbalanced development, different regions are facing different challenges, leading to different $\mathrm{CO}_{2}$ emission patterns. Therefore, it is necessary to undertake a microscopic study so that appropriate mitigation policies for the transportation sector can be raised by considering local realities. Secondly, most of these studies only use the LMDI method to analyze the influences of driving forces on $\mathrm{CO}_{2}$ emissions. It is generally acknowledged that the LMDI method is appropriate for explaining the influences of variation rather than the stock $[50,51]$. Thus, the whole responsiveness of environmental pressure to economic output change (especially the stock) is largely ignored. Under such circumstances, this paper aims to fill such a research gap by incorporating the decoupling index analysis into the framework of LMDI. There are two main advantages by combining these two approaches. On the one hand, the stock explanatory limitation of the LMDI method could be eliminated [52]. On the other hand, by combining index decomposition results and the decoupling index (especially the decoupling effort index), we can identify which factors and to what extent enhance or curtail carbon emissions $[7,52,53]$.

\section{Materials and Methods}

\section{Estimation of Transport Sector's $\mathrm{CO}_{2}$ Emissions}

By applying the methods that were proposed by the Intergovernmental Panel on Climate Change (IPCC) 2006 guidelines [54], this paper estimates $\mathrm{CO}_{2}$ emissions related to the end-use energy consumption in Xinjiang's transport sector. The total energy-related $\mathrm{CO}_{2}$ emissions can be calculated based on energy consumption and the 
Table 1. $\mathrm{CO}_{2}$ emission factors of various energy sources.

\begin{tabular}{|c|c|c|c|c|}
\hline Fuel type & $\begin{array}{c}\mathrm{LCV}(\mathrm{KJ} / \mathrm{kg} \\
\text { or } \mathrm{KJ} / \mathrm{m}^{3}\end{array}$ & $\begin{array}{c}\text { Oxidation } \\
\text { rate }\end{array}$ & $\begin{array}{c}\text { Potential carbon content } \\
(\mathrm{kg} \mathrm{C} / \mathrm{GJ})\end{array}$ & $\begin{array}{c}\mathrm{CO}_{2} \text { Emissions Factor } \\
\left(\mathrm{tCO}_{2} / \mathrm{ton}_{\left.\mathrm{or} 10^{3} \mathrm{~m}^{3}\right)}\right.\end{array}$ \\
\hline Coal & 28,435 & 0.928 & 29.5 & 2.860 \\
\hline Gasoline & 43,070 & 0.986 & 18.9 & 2.925 \\
\hline Kerosene & 43,070 & 0.980 & 19.6 & 3.033 \\
\hline Diesel oil & 42,652 & 0.982 & 20.2 & 3.096 \\
\hline Natural gas & 38,931 & 0.990 & 15.3 & 2.132 \\
\hline
\end{tabular}

fraction of oxidized carbon by fuel and emission factors, as shown in the following equation:

$$
C^{t}=\sum_{i} C_{i}^{t}=\sum_{i} E_{i}^{t} \times O_{i} \times E F_{i}
$$

...where $C^{t}$ denotes the total $\mathrm{CO}_{2}$ emissions in year $t$ and is quoted in 10,000 tons; $C_{i}^{t}$ means the $\mathrm{CO}_{2}$ emissions based on fuel type $i$ in year $t$, while $i=1,2,3,4,5,6$ denotes the main six fuel types: coal, gasoline, kerosene, diesel oil, natural gas, and electricity; $E_{i}^{t}$ represents the consumption of fuel type $i$ in year $t(\mathrm{GJ}) ; O_{i}$ denotes the fraction of the carbon oxidized by fuel type $i$; and $E F_{i}$ denotes the $\mathrm{CO}_{2}$ emissions coefficient of fuel type $i$. The potential carbon content, oxidation rate, and $\mathrm{CO}_{2}$ emission factors are listed in Table 1.

According to the regional division of the State Grid, which was released by the China National Development and Reform Commission, Xinjiang belongs to the northwest regional power grid. Since 2008 China has successively promulgated baseline emission factors for different regional power grids. Table 2 shows the baseline emission factor of the northwest power grid over the period 2008-2013. Based on the baseline emission factor of the northwest power grid and previous studies [54, 56-59], the emission factor of Xinjiang electric power is determined to be $1.0175 \mathrm{tCO}_{2} / \mathrm{MWh}$.

\section{Index Decomposition Analysis}

Considering the main purpose and data availability, the LMDI was chosen for this study. Combined with the expanded Kaya identity [60], this study applied both period-wise LMDI and time-wise LMDI to probing the driving factors of $\mathrm{CO}_{2}$ emission from the transport sector in Xinjiang.

Based on previous research $[43,61]$, changes in energyrelated $\mathrm{CO}_{2}$ emission may be studied by quantifying the contributions from changes in seven different factors. The aggregate $\mathrm{CO}_{2}$ emission from the transport sector can be evaluated as follows:

$$
\begin{gathered}
C=\sum_{i} C_{i}=\sum_{i} \frac{C_{i}}{E_{i}} \cdot \frac{E_{i}}{E} \cdot \frac{E}{T O} \cdot \frac{T O}{S O} \cdot \frac{S O}{G D P} \cdot \frac{G D P}{P} \cdot P \\
=\sum_{i} F_{i} \cdot M_{i} \cdot I \cdot T S \cdot I S \cdot G \cdot P
\end{gathered}
$$

...where $C$ represents the total energy-related $\mathrm{CO}_{2}$ emission from the transport sector; $i$ is the type of energy; and $E$ refers to the final energy consumption in the transport sector. $T O$ and $S O$ are added values of transport output and service industry output, respectively; $G D P$ is gross domestic production in Xinjiang; and $P$ denotes total population in Xinjiang. Accordingly, total carbon emissions from the transportation sector can be decomposed into seven effects: emission factor effect $(F)$; energy mix effect $(M)$; energy intensity effect $(I)$; internal structural effect in tertiary industry; the proportion of transportation output in total service industry (TS); industrial structure effect, estimated by the proportion of service industry output in total GDP of Xinjiang Province $(I S)$; economic effect per capita GDP as the indicator for it $(G)$; and population effect $(P)$.

According to the LMDI method [43, 62-63], the changes of $\mathrm{CO}_{2}$ emissions from year 0 to year $T$ can be expressed in additive form as follows:

$$
\begin{gathered}
\Delta C_{t o t}=C^{t}-C^{0}=\Delta C_{F}+\Delta C_{M}+\Delta C_{I}+\Delta C_{T S}+ \\
+\Delta C_{I S}+\Delta C_{G}+\Delta C_{P}
\end{gathered}
$$

Table 2. Baseline emission factor of northwest power grid ( $\left.\mathrm{tCO}_{2} / \mathrm{MWh}\right)$.

\begin{tabular}{|c|c|c|c|c|c|c|}
\hline Year & 2008 & 2009 & 2010 & 2011 & 2012 & 2013 \\
\hline Northwest power grid & 1.1225 & 1.0246 & 0.9947 & 1.0001 & 0.9913 & 0.9720 \\
\hline
\end{tabular}




$$
\begin{aligned}
\Delta C_{F}^{T} & =\sum_{i=1}^{n} w_{i} \ln \frac{F^{T}}{F^{0}} \\
\Delta C_{M}^{T} & =\sum_{i=1}^{n} w_{i} \ln \frac{M^{T}}{M^{0}} \\
\Delta C_{T S}^{T} & =\sum_{i=1}^{n} w_{i} \ln \frac{T S^{T}}{T S^{0}} \\
\Delta C_{I S}^{T} & =\sum_{i=1}^{n} w_{i} \ln \frac{I S^{T}}{I S^{0}} \\
\Delta C_{G}^{T} & =\sum_{i=1}^{n} w_{i} \ln \frac{G^{T}}{G^{0}} \\
\Delta C_{P}^{T} & =\sum_{i=1}^{n} w_{i} \ln \frac{P^{T}}{P^{0}}
\end{aligned}
$$

The term $w_{i}$ is the estimated weight for the addictive LMDI methods. This weight is defined as:

$$
w_{i}=\frac{C_{i}^{T}-C_{i}^{0}}{\ln C_{i}^{t}-\ln C_{i}^{0}}
$$

The index variable " $t$ " and " 0 " denote the examined year and the base year. $\Delta C_{M}^{T}$ denotes the changes of carbon emissions from the energy mix effect; $\Delta C_{I}^{T}$ represents the changes from energy intensity effect; $\Delta C_{T S}^{T}$ indicates the internal structural effect in the tertiary industry; $\Delta C_{I S}^{T}$ is the changes from industrial structure; and $\Delta C_{G}^{T}$ and $\Delta C_{P}^{T}$ refer to the changes from economic effect and population effect, respectively. $\Delta C_{F}^{T}$ denotes the changes of carbon emissions from the emission factor effect. In this study, we assume that the emission factors of various energy sources were unchanged during the study period, thus this term can be regarded as zero. Therefore, we rewrite Eq. (3) as:

$$
\begin{aligned}
\Delta C_{\text {tot }}=C^{T}-C^{0}= & \Delta C_{M}+\Delta C_{I}+\Delta C_{T S}+\Delta C_{I S}+ \\
& +\Delta C_{G}+\Delta C_{P}
\end{aligned}
$$

Decoupling Index

\section{Decoupling Elasticity Index}

According to Tapio [53], decoupling index of $\mathrm{CO}_{2}$ emissions from economic growth can be expressed as elasticity values under 1.0 , where the percentage change of $\mathrm{CO}_{2}$ emissions is divided by the percentage change of GDP in a given period. We use $\delta$ to indicate the decoupling index, and it can be expressed as:

$$
\delta=\frac{\% \Delta C}{\% \Delta T O}=\frac{\Delta C / C}{\Delta T O / T O}
$$

Based on the studies of Vehmas et al. [64] and Tapio [53], the eight degrees of coupling and decoupling can be distinguished. Specifically, the growth rate of $\mathrm{CO}_{2}$ emissions and GDP can be coupled, decoupled, or negatively decoupled. The decoupling state can be further divided into three sub-states: in weak decoupling (WD), $\mathrm{CO}_{2}$ emissions and GDP both increased $(0 \leq \delta<0.8)$; strong decoupling (SD) when GDP grows and $\mathrm{CO}_{2}$ emissions decreases $(\delta<0)$; and recessive decoupling $(\mathrm{RD})$ when GDP and $\mathrm{CO}_{2}$ emissions both decrease $(\delta>1.2)$. Similarly, negative decoupling (ND) includes three subcategories: in weak negative decoupling (WD), both $\mathrm{CO}_{2}$ emissions and GDP decreased $(0 \leq \delta<0.8)$; in expansive negative decoupling (END), $\mathrm{CO}_{2}$ emissions and GDP both increased $(\delta>1.2)$; for strong negative decoupling (SND), $\mathrm{CO}_{2}$ emissions increased and GDP decreased $(\delta<0)$. The growth of $\mathrm{CO}_{2}$ emissions and GDP can be positive or negative, so the last two states are expressed as expansive coupling (EC: $0.8 \leq \delta<1.2)$ and recessive coupling (RC: $0.8 \leq \delta<1.2$ ), respectively.

\section{Decoupling Effort State}

In general, measures of $\mathrm{CO}_{2}$ emissions reduction include improving energy efficiency, switching fuel to cleaner energy types, upgrading industrial structure, and controlling population. According to the definition given by Diakoulaki and Mandaraka [65], the effort is a general term referring to all actions directly or indirectly reducing $\mathrm{CO}_{2}$ emissions. Thus, the relative contribution of each factor was identified in the overall decoupling progress. Therefore, the effort $(\Delta E)$ can be represented as the sum of the five explanatory factors, then we rewrite Eq. (6) as follows:

$$
\Delta E=\Delta C_{\text {tot }}-C_{G}=\Delta C_{M}+\Delta C_{I}+\Delta C_{T S}+\Delta C_{I S}+\Delta C_{P}
$$

In order to assess the degree to which these efforts are effective in term of the dissociation between $\mathrm{CO}_{2}$ emissions and GDP growth, we defined the decoupling effort index $D$ as the fraction of output effect that is offset by emission reduction efforts:

$$
\begin{gathered}
D=-\frac{\Delta E}{\Delta C_{G}}=-\frac{\Delta C_{M}}{\Delta C_{G}}-\frac{\Delta C_{I}}{\Delta C_{G}}-\frac{\Delta C_{T S}}{\Delta C_{G}}-\frac{\Delta C_{I S}}{\Delta C_{G}}- \\
-\frac{\Delta C_{P}}{\Delta C_{G}}=D_{M}+D_{I}+D_{T S}+D_{I S}+D_{P}
\end{gathered}
$$

If $D_{t} \geq 1$, which implies a strong decoupling effort, putting it in another way, the total $\mathrm{CO}_{2}$ emissions reduction 
effect is greater than the driving effect of GDP growth. If $0<D_{t}<1$, which indicates the relative decoupling effort, in other words, it means the $\mathrm{CO}_{2}$ emissions reduction effect is weaker than the driving effect. If $D_{t} \leq 0$, which denotes no decoupling effort, we can say that the possible inhabiting factors do not reduce $\mathrm{CO}_{2}$ efficiently but increase instead.

\section{Data Description}

According to the Classification of National Economic Industries [66], the transportation sector in this paper is composed of transportation, storage, and postal services. Total energy consumption from the sector was collected from the China Energy Statistical Yearbook (CESY) published by the National Bureau of Statistic (NBS, 1990-2015) [67]. Six types of fuels were considered for computation in this study: coal, gasoline, kerosene, diesel oil, natural gas, and electricity, and these data were quoted from the energy balance table of XSY (Xinjiang Statistical Yearbook) [68]. Population data and GDP values from the transportation sector and from the service industry were also extracted from XSY. In order to eliminate the inflation effect, we converted the economic output values from the current price to the constant price in 1990 using GDP indices (preceding year $=100$ ).

\section{Results and Discussion}

The Trajectory of $\mathrm{CO}_{2}$ Emissions
from Transportation

\section{Macro-Level: Total and Per Capita $\mathrm{CO}_{2}$ Emissions from Transportation}

According to Eq. (1), total $\mathrm{CO}_{2}$ emissions from transportation and the per capita $\mathrm{CO}_{2}$ emissions in Xinjiang during 1990-2014 were calculated, and the results are shown in Fig. 2. In terms of the variation characteristics, the development of $\mathrm{CO}_{2}$ emissions from the transportation sector in Xinjiang since 1990 can be divided into two phases: a relatively slowly increased phase (before 2004) and a fast increased phase (after 2004). As such, the per capita $\mathrm{CO}_{2}$ emissions followed a similar trend. In the first phase, the average growth rates of $\mathrm{CO}_{2}$ emissions and per capita $\mathrm{CO}_{2}$ emissions were $7.53 \%$ and $5.38 \%$, respectively. However, these indicators were up to $12.83 \%$ and $11.05 \%$ during 2004-14, namely the second phase. The significant difference of growth rate between these two phases can be explained by the Western Development Strategy, which was launched in 2001. Due to the hysteresis of transportation infrastructure investment, the promotion on transportation energy consumption didn't take effect until three years later.

\section{Micro-Level: Carbon Emission Structure}

Energy consumption mix has an important influence on carbon emissions. Figure 3 illustrates the $\mathrm{CO}_{2}$ emissions from each fuel type during 1990-2014. Three important results can be drawn from Fig. 3. Firstly, as a whole, the carbon emissions from all fuel types kept increasing in the study period, especially since 2004. This indicates that economic abidance grows quickly, bringing new opportunity for transportation. According to XSY, the lengths of road transport lines has increased markedly since 2004. Moreover, road traffic is the main method of transportation in Xinjiang. Therefore, the $\mathrm{CO}_{2}$ emissions due to fuel combustion rose sharply. Secondly, it is diesel oil rather than gasoline that turns out to be the biggest emitter of carbon emissions. This is caused by increased diesel combustion due to the usage of trucks for road freight transport, which was, is, and will remain the dominant mode of transportation in Xinjiang. Thirdly, as for cleaner energies, namely natural gas and electricity, they had steady growth but still account for a very small slice among all fuel types. However, it should be noted that since 2012, almost half a million cars and buses and more than 100,000 private cars were using liquid natural gas (LNG) for eco-friendliness and higher efficiency. This is potentially a fundamental way to reduce $\mathrm{CO}_{2}$ emissions in Xinjiang.

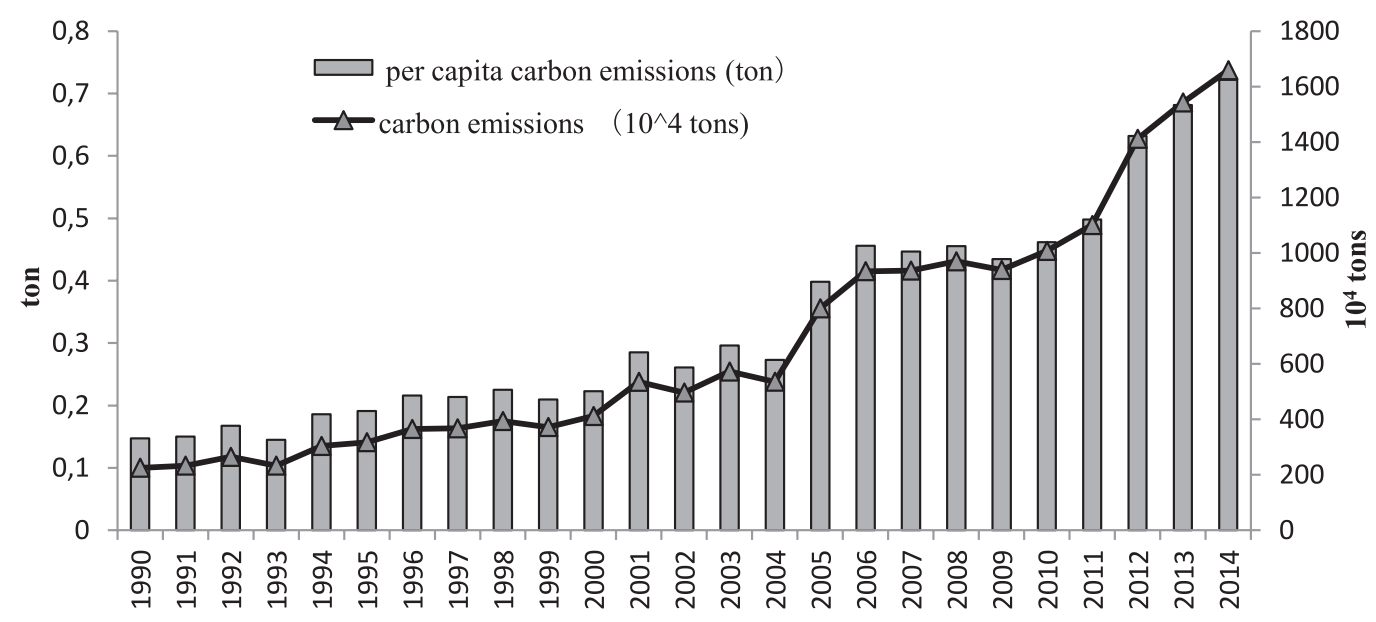

Fig. 2. Carbon emissions of the transportation sector in Xinjiang, 1990-2014. 


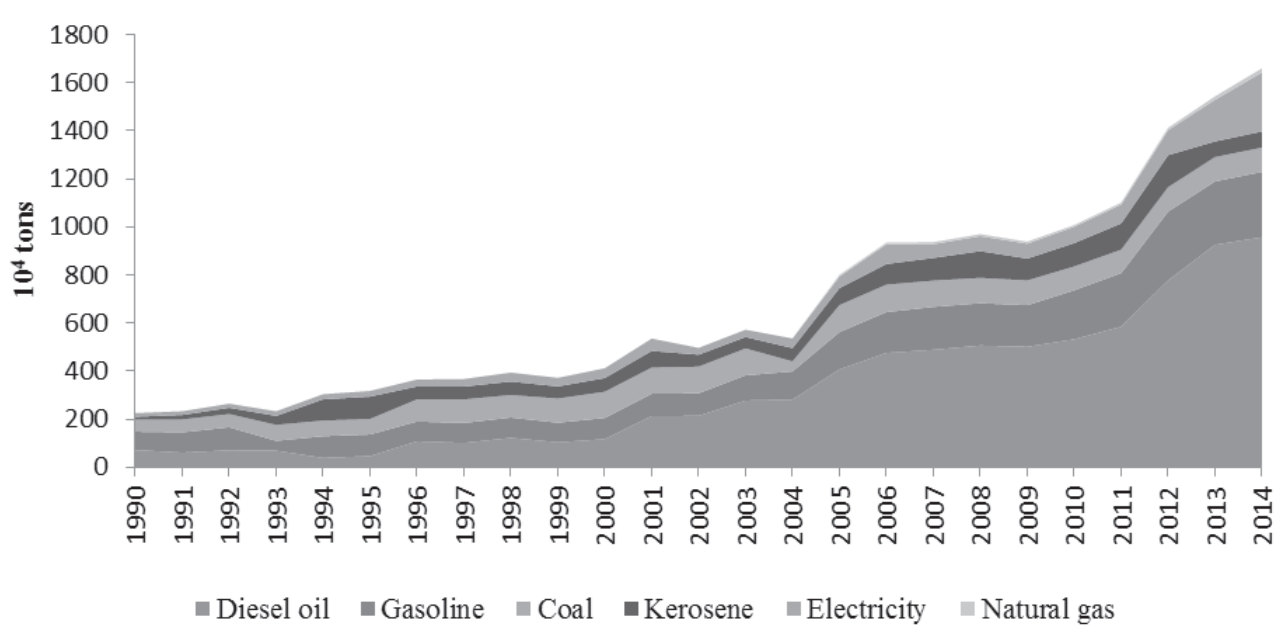

Fig. 3. Carbon emissions from six main energy types from 1990 to 2014.

\section{Reasons for Carbon Emissions from the Transportation Sector in Xinjiang}

The decomposition results were reported in Fig. 4. The results are useful for identifying the main reasons for $\mathrm{CO}_{2}$ emission variations that took place in Xinjiang's transportation sector over the period 1990-2014.

According to Fig. 4, the economic effect has been the most important driver of energy-related $\mathrm{CO}_{2}$ emissions increases. Moreover, the economic effect was gradually enhanced during the study period. In particular, it has grown from $12.7610^{4}$ tons in 1990 to $128.410^{4}$ tons in 2014 , with the highest value ( $132.510^{4}$ tons) in 2013. This indicates that economic growth in the transport sector had been dependent on energy consumption. Over the past decades, Xinjiang's transportation sector has developed rapidly. According to XSY, the length of transport routes has grown rapidly. Specifically, the length of railways in operation increased by 4,417 km during 1990-2014, with the annual growth rate of $6.3 \%$. What's more, the lengths of highways and total civil aviation routes have faster annual growth rates of $8.4 \%$ and $7.6 \%$, respectively. The increase in the length of transport routes has greatly contributed to the development of the logistics industry, which led to a rapid increase of carbon emissions in the transportation sector.

In addition to economic effect, it should be noted that the population effect also plays a positive role in the increment of $\mathrm{CO}_{2}$ emissions. Furthermore, the trend of this role has continuously strengthened in the study period. This result is quite different from most of the existing conclusions in which the role of the population effect has been weakened. In China, Xinjiang is a special area due to it not only being a frontier region, but also a gathering area of ethnic minorities (especially the Uigur nationality). In China, the population policies which were implemented in ethnic minority areas were more liberal than those of Hans. The implement of promote population fertility policies resulted in a more rapidly natural population growth rate. In the study period, the natural growth rate of Xinjiang's population was approximately $12.48 \%$. This rate is $4.2 \%$ higher than the national average, which was only $8.28 \%$. The growth in population inevitably drives the increase of transportation-related energy consumption, which correspondingly elevates the level of $\mathrm{CO}_{2}$ emissions.

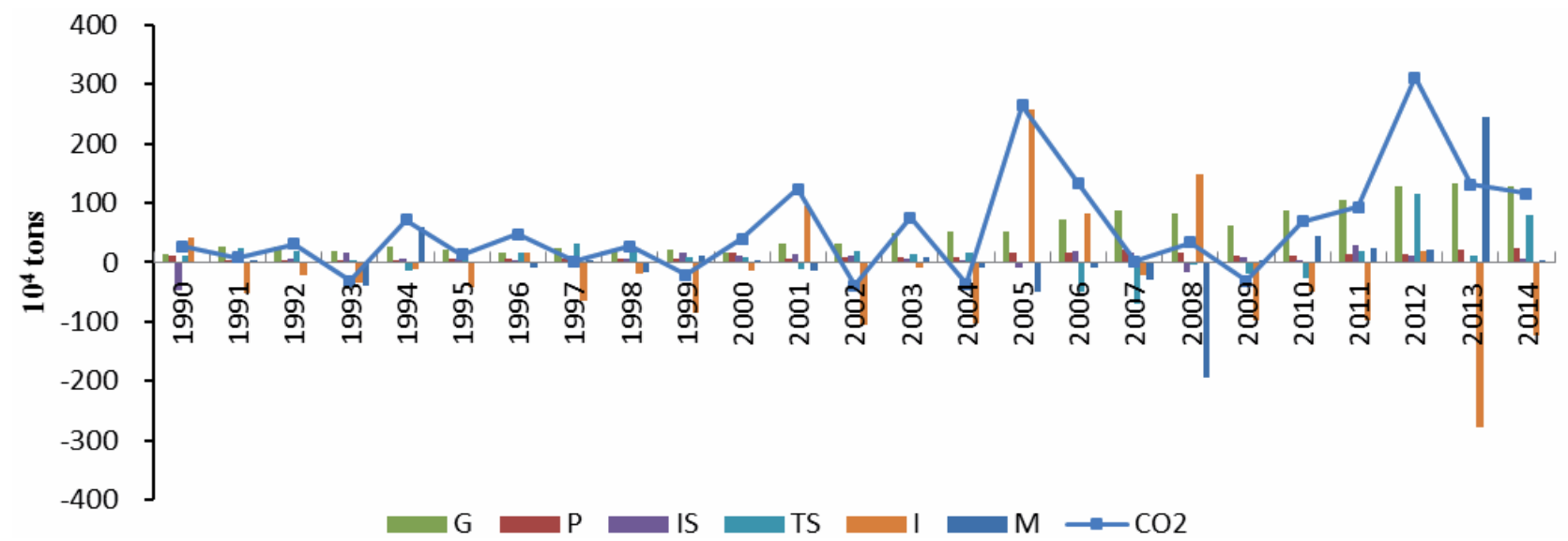

Fig. 4. Driving forces of $\mathrm{CO}_{2}$ emissions from Xinjiang's transport sector during 1990-2014. 
Contrary to the above-mentioned effects, the other four effects - namely energy mix effect, energy intensity effect, internal structural effect, and industrial structure effect more or less play a role in inhibiting carbon emissions. In other words, energy structure optimization, industrial structure upgrading, and energy efficiency improvement can inhibit the increase of carbon emissions on different levels. However, it should be noted that the structural effects (include $T S$ and $I S$ ) are far from fully playing the role in impeding $\mathrm{CO}_{2}$ emissions. For example, the values of industrial structural effect were negative only in 1990, 2005, 2008, and 2013, which sufficiently indicates that the adjustment of the industrial structure in Xinjiang is both urgent and arduous.

With regard to energy mix effect, the role of promotion and inhibition match each other in strength. In particular, the energy mix effect increased $\mathrm{CO}_{2}$ emissions over 13 years while reducing $\mathrm{CO}_{2}$ emissions in the remaining 12 years. Fig. 4 shows that from 2004 to 2008 , the energy mix effect significantly inhibited $\mathrm{CO}_{2}$ emissions. Especially in 2008, the value of this effect was low (to -195.43), and it even exceeded the promoting effect of the economic effect. The underlying cause may be the widespread use of natural gas in Xinjiang's transport sector.

Furthermore, it can be found that the energy intensity effect proved to be a major inhibiting factor as far as factors are considered in this study. As the ration of energy consumption and GDP, the energy intensity indicator is suited to account for energy saving and energy efficiency measures. Over the period of 1990-2014, energy intensity in Xinjiang's transport declined from 15.41 tce/10,000 yuan to 4.49 tce/10,000 yuan with an average decline rate of $5.01 \%$. As Fig. 4 shows, the decreased energy intensity caused -5.71 million tons of carbon emissions reduction accumulatively. Since 2008, Xinjiang has attached great importance to energy conservation and emission reduction in the transportation sector, which has resulted in the improvement of technical efficiency and resource use efficiency. Thus, over the period of 2009-14, the energy intensity effect has played a more important role in curbing $\mathrm{CO}_{2}$ emissions.

\section{Analysis of Decoupling Indexes}

In this paper, we combined the decoupling index analysis with the LMDI method. The decoupling index performed well when investigating the stock of $\mathrm{CO}_{2}$ emissions and brought insight into the in-depth relationship between $\mathrm{CO}_{2}$ emissions and economic growth. In this section, this study shows the results of decoupling state from two perspectives: decoupling elasticity index and decoupling effort index, respectively. Moreover, based on the results of the decoupling state, we will further decompose the decoupling effort index to identify which factors promote or hinder the increase of $\mathrm{CO}_{2}$ emissions as well as to what extent.

\section{Decoupling State}

Based on the decoupling index and decoupling effort index, the relationship between economic growth in Xinjiang's transportation sector and $\mathrm{CO}_{2}$ emissions is explored deeply. Table 3 shows the results of decoupling analysis on two different time scales using one-and fiveyear plans. The reason for selecting the five-year time scale is that it corresponds to China's five-year development plans.

The decoupling state in each year was determined by the values of $\delta$. As shown in Table 3, the elasticity values $(\delta)$ demonstrated volatile fluctuations, ranging from -0.65 in 1993 to 5.48 in 2005. However, the amplitude of the fluctuation is gradually diminishing. Generally speaking, the transport sector in Xinjiang had witnessed a relatively obvious tendency toward decoupling. In particular, the decoupling state moved from weak decoupling in 1991-2000 with short-term volatility (SD in 1993 and 1999) to weak decoupling in 2001-2014. From the frequencies of the various decoupling states, we can find that during the 24-year study, WD appeared 11 times with the highest frequency, followed by SD (five times), EC (four times), and END (expansive negative decoupling, four times). Therefore, we can conclude that decoupling has not yet been achieved in Xinjiang's transportation sector.

From the perspective of decoupling effort index, which demonstrated much more volatile fluctuations, the results of decoupling state can be obtained. Specifically, the index of decoupling effort ranges from -4.06 in 2005 to 2.58 in 1993, which is in line with the results of the decoupling index. In Table 3, it is worth noting that those of decoupling index of 10 years in 24 years were "no decoupling effort," indicating that neither improvement of energy efficiency nor structural adjustment plays its due role in promoting the progress of decoupling in these years.

Generally speaking, the results of the decoupling index and decoupling effort index are similar through comparative analysis. Moreover, Xinjiang's transport had witnessed a fluctuant decoupling progress with weak decoupling as the theme. It should be noted that over the period of 2001-2005, the decoupling level between transport output and $\mathrm{CO}_{2}$ emissions was relatively low, especially when compared with that in 1991, in which case it remained as weak decoupling. According to XSY, the output of Xinjiang's transport sector has experienced a slow increase and the average growth rate during 2001-2005 was down to $0.21 \%$. However, the $\mathrm{CO}_{2}$ emissions had increased sharply over the same period. It can be seen from Table 3 that the increment of $\mathrm{CO}_{2}$ emissions reached 2.65 million tons during 2001-2005, with the average growth rate being $10.7 \%$. As such, the decoupling effort state from 2001 to 2005 was "no decoupling effort." Similarly, the same situation occurred during 2011-2014. In 2000, the Strategy of West China Development was implemented in Xinjiang. And in 
Table 3. Decoupling state and decoupling effort state.

\begin{tabular}{|c|c|c|c|c|c|c|c|}
\hline Time series & Year & $\delta$ & $\Delta C$ & $\triangle T O$ & Decoupling state & $D$ & Decoupling effort state \\
\hline \multirow{24}{*}{ One Year } & 1990-1991 & 0.120 & 7.763 & 4.213 & WD & 0.713 & Weak \\
\hline & 1991-1992 & 0.548 & 31.457 & 4.636 & WD & -0.189 & None \\
\hline & $1992-1993$ & -0.651 & -31.552 & 4.297 & SD & 2.579 & Strong \\
\hline & 1993-1994 & 3.134 & 70.875 & 2.694 & END & -1.799 & None \\
\hline & 1994-1995 & 0.230 & 13.641 & 5.942 & WD & 0.370 & Weak \\
\hline & $1995-1996$ & 1.153 & 47.613 & 4.734 & $\mathrm{EC}$ & -2.074 & None \\
\hline & 1996-1997 & 0.031 & 2.221 & 8.064 & WD & 0.905 & Weak \\
\hline & $1997-1998$ & 0.411 & 26.399 & 8.612 & WD & -0.253 & None \\
\hline & 1998-1999 & -0.373 & -21.623 & 8.450 & SD & 2.015 & Strong \\
\hline & $1999-2000$ & 0.742 & 39.766 & 9.550 & WD & -1.396 & None \\
\hline & $2000-2001$ & 3.149 & 123.271 & 7.208 & END & -2.862 & None \\
\hline & 2001-2002 & -0.504 & -38.596 & 11.880 & SD & 2.182 & Strong \\
\hline & $2002-2003$ & 1.008 & 75.622 & 14.339 & $\mathrm{EC}$ & -0.556 & None \\
\hline & $2003-2004$ & -0.423 & -36.538 & 16.504 & SD & 1.720 & Strong \\
\hline & 2004-2005 & 5.481 & 264.294 & 11.322 & END & -4.061 & None \\
\hline & $2005-2006$ & 2.329 & 134.185 & 9.873 & END & -0.830 & None \\
\hline & 2006-2007 & 0.038 & 2.159 & 8.967 & WD & 0.975 & Weak \\
\hline & $2007-2008$ & 0.409 & 33.301 & 13.569 & WD & 0.601 & Weak \\
\hline & 2008-2009 & -0.461 & -31.314 & 11.867 & SD & 1.506 & Strong \\
\hline & $2009-2010$ & 0.928 & 68.809 & 14.331 & $\mathrm{EC}$ & 0.215 & Weak \\
\hline & $2010-2011$ & 0.536 & 93.306 & 33.861 & WD & 0.123 & Weak \\
\hline & 2011-2012 & 1.172 & 310.919 & 55.331 & $\mathrm{EC}$ & -1.429 & None \\
\hline & $2012-2013$ & 0.787 & 131.114 & 33.621 & WD & 0.011 & Weak \\
\hline & $2013-2014$ & 0.469 & 116.376 & 51.286 & WD & 0.094 & Weak \\
\hline \multirow{5}{*}{$\begin{array}{l}\text { Five-Year } \\
\text { Plan }\end{array}$} & 1991-1995 & 0.388 & 84.421 & 17.568 & WD & 0.235 & Weak \\
\hline & $1996-2000$ & 0.152 & 46.763 & 34.726 & WD & 0.035 & Weak \\
\hline & $2001-2005$ & 0.760 & 264.782 & 54.045 & WD & -0.793 & None \\
\hline & $2006-2010$ & 0.236 & 72.954 & 48.733 & WD & 0.474 & Weak \\
\hline & 2011-2014 & 0.831 & 558.409 & 140.239 & $\mathrm{EC}$ & -0.316 & None \\
\hline
\end{tabular}

2001, China successfully joined the WTO. Moreover, in 2013 the Chinese government put forward the "One Belt, One Road" initiative. The implementation of this series of policies promoted the construction of Xinjiang transportation infrastructure greatly. In turn, the largescale expansion of transportation inevitably has given rise to more carbon emissions.

\section{The Decomposition of Decoupling Effort Index}

The decoupling effort index is defined as the ratio of the sum of energy mix effect, energy intensity effect, internal structural effect, industrial effect, and population effect to the change of economic effect. During 1991-2014, the economic effect caused the continuous increase of $\mathrm{CO}_{2}$ emissions, which showed in turn that this effect played a crucial role in the decoupling block. Fig. 5 presents the decoupling effort index together with the contribution of each single type of effort.

In order to illustrate the results clearly and consider the significant influence of the Five-Year Plan in Xinjiang, the decomposition results of decoupling effort index are shown in Fig. 5 on a five-year time scale.

As shown in Fig. 5, the decoupling effort index ranging from -0.79 during 2001-2005 to 0.47 during 


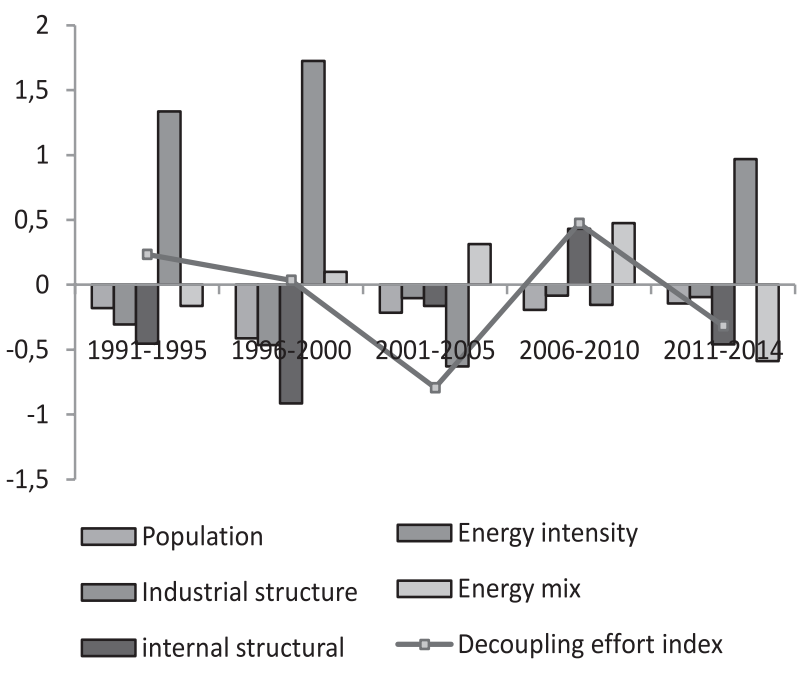

Fig. 5. Decomposition of decoupling effort index on $\mathrm{CO}_{2}$ emissions in Xinjiang's transportation sector, 1991 to 2014.

2006-2010, indicating that the decoupling progress in Xinjiang's transport sector demonstrates slight fluctuations. Moreover, there are three "weak decoupling" efforts and two "no decoupling" efforts over the study periods. In order to identify the contribution of each single type of effort, this study analyzed each factor separately below.

The most important factor explaining the dissociation refers to the energy intensity effect except for the periods 2001-2005 and 2006-2010. During 1991-2000, the energy intensity effect was even greater than one, which implies the promoting effect on decoupling between $\mathrm{CO}_{2}$ emissions and economic output. Overall, the energy intensity effect accounts for $45.5 \%$ of the total decoupling effort index during 1991-2014. Generally, owing to optimization of transportation structure (more rail transport), improvement of energy use efficiency of vehicles, and relatively developed transport infrastructure in urban areas, the energy intensity in Xinjiang's transport declines significantly. Therefore, as the most important inhibiting factor to carbon emissions, energy intensity has proven to be the biggest contributor to the decoupling relationship.

As for the energy mix effect, it played a positive role in decoupling progress from 1996 to 2010. On the contrary, during the period of 1991-1995 and 2011-2014, it hinders the decoupling process. Changes in the proportion of various energy consumptions are the main reason for this phenomenon. The fuel in the transport sector toward natural gas and electricity from gasoline and petroleum products, which may explain the fact that the energy mix effect promotes the progress of decoupling. However, according to XSY, the rapid growth in the proportion of diesel consumption impedes the decoupling process from 2011 to 2014.

The influence of structure on the process of decoupling has been analyzed from two perspectives, namely industrial structure effect and internal structure effect.
It can be seen from Fig. 5 that both industrial structure effect and internal structure effect play negative roles in the decoupling progress with an exception of industrial structure effect during 2006-2010. Moreover, the industrial structure effect plays a more pronounced role compared with the internal structure effect. This fully indicates that optimizing the industrial structure can make a greater contribution to carbon emission reduction.

The population effect generally results in a constant increase in $\mathrm{CO}_{2}$ emissions over the study period, which does not contribute to decoupling. In other words, this means that ongoing population growth hinders decoupling. Although over decades China has implemented strict family planning policies, the natural population growth rate is still high in Xinjiang. According to XSY, the average growth is $11.6 \%$ over the examined period, which is about two times the average value in the whole country.

\section{Conclusions}

Due to vast territory and rapid economic development, energy-related carbon emissions have increased rapidly in Xinjiang's transportation sector. To clarify, the driving factors of carbon emissions are significant for energy conservation and emission reduction as well as the development of low-carbon transportation. This paper calculated the total carbon emissions of Xinjiang's transportation sector over the period of 1990-2014. Then, in order to identify the factors promoting or hiding decoupling progress as well as to what extent, an indepth analysis was conducted by combining the additive LMDI method, the decoupling elasticity index, and the decoupling effort index. The main conclusions obtained from our research are as follows.

During 1991-2014, both the total carbon emissions and per capita carbon emissions in Xinjiang's transportation sector exhibited an obvious upward trend. Specifically, the total carbon emissions increased from 2.25 million tons in 1990 to 16.59 million tons in 2014, with an average annual growth rate of $8.7 \%$. The per capita carbon emissions increased from $0.14 \mathrm{t}$ to $0.72 \mathrm{t}$, representing an average annual growth rate of $6.8 \%$. However, the energy intensity has declined constantly over the study period. As for the energy mix, diesel oil rather than gasoline proved to be the biggest emitter of carbon emissions due to the dominant position of large trucks in Xinjiang's transportation system.

Economic growth turned out to be the main contribution to increased $\mathrm{CO}_{2}$ emissions in Xinjiang's transportation sector. In addition, the ongoing population also plays a positive role in the increment of $\mathrm{CO}_{2}$ emissions. On the contrary, energy intensity has proven to be the most important inhibiting factor to $\mathrm{CO}_{2}$ emissions. It was decreased by -6.12 million tons of $\mathrm{CO}_{2}$ emissions during 1991-2014. However, when considering the structure effect, neither industrial structure nor internal structural effect reduced $\mathrm{CO}_{2}$ emissions effectively. Moreover, 
because the diesel-based energy mixes in Xinjiang's transport was not improved over the study period, the energy mix effect was increased by 0.46 million tons of $\mathrm{CO}_{2}$ emissions over the study period.

Xinjiang's transportation had witnessed a fluctuant decoupling progress with the weak decoupling is the theme. In general, the results of the decoupling index and decoupling effort index are similar through comparative analysis. It is worth noting that during 2011-2014, the coupling relationship between $\mathrm{CO}_{2}$ emissions and transport output has been further strengthened. This may be caused by the improvement of transportation infrastructure and the rapid development of the logistics industry in recent years.

As shown by the decomposition results of the decoupling effort index, the energy intensity effect is the most important factor explaining the dissociation, indicating that improving energy efficiency is the primary means of decoupling. However, the structure effect, including industrial structure effect and internal structure effect, does not play its due role, especially the industrial structure effect. This shows that there is great potential in optimizing and upgrading the industrial structure. In addition, both population effect and energy mix effect play a positive role in the decoupling progress apart from individual years. Therefore, rational control of population size and effective adjustment of energy structure were important measures for realizing low-carbon transportation in Xinjiang.

\section{Acknowledgements}

The current work is supported by the Foundation of the Director of Xinjiang Institute of Ecology and Geography, Chinese Academy of Sciences (Y173051001) and (Y035112001), the Key construction discipline of Shanxi Province (No. XK2014012), and Ring Fenced Funding of Research on Endogenous Development Path of Yuncheng under the regional cooperation of Golden Triangle in the Yellow River (No. 4, 2014).

\section{References}

1. WANG Q., CHEN X. Energy policies for managing China's carbon emission. Renewable and Sustainable Energy Reviews, 50, 470, 2015.

2. World energy outlook 2014. International Energy Agency, 2014, Available online: http://URL (accessed on 15 September 2016).

3. WANG S., FANG C., WANG Y. Spatiotemporal variations of energy-related $\mathrm{CO}_{2}$ emissions in China and its influencing factors: An empirical analysis based on provincial panel d ata. Renewable and Sustainable Energy Reviews, 55, 505, 2016.

4. XIAO B., NIU D., GUO X. The Driving Forces of Changes in $\mathrm{CO}_{2}$ Emissions in China: A Structural Decomposition Analysis. Energies, 9 (4), 259, 2016.

5. TAN X., DONG L., CHEN D., GU B., ZENG Y. China's regional $\mathrm{CO}_{2}$ emissions reduction potential: A study of
Chongqing city. Applied Energy, 162, 1345, 2016.

6. DENG X., YU Y., LIU Y. Temporal and Spatial Variations in Provincial $\mathrm{CO}_{2}$ Emissions in China from 2005 to 2015 and Assessment of a Reduction Plan. Energies, 8 (5), 4549, 2015.

7. DONG J.F., DENG C., WANG X.M., ZHANG X.L. Multilevel Index Decomposition of Energy-Related Carbon Emissions and Their Decoupling from Economic Growth in Northwest China. Energies, 9 (9), 680, 2016.

8. TSAO R. One Belt One Road. Chinese American Forum. 31 (1), 11, 2015.

9. ZHANG Y.L. One Belt, One Road: A Chinese View. Global Asia, 10 (3), 8, 2015.

10. HUO J., YANG D., ZHANG W., WANG F., WANG G., FU Q. Analysis of influencing factors of $\mathrm{CO}_{2}$ emissions in Xinjiang under the context of different policies. Environmental Science \& Policy, 45, 20, 2015.

11. GUO B., GENG Y., DONG H., LIU Y. Energy-related greenhouse gas emission features in China's energy supply region: the case of Xinjiang. Renewable and Sustainable Energy Reviews, 54, 15, 2016.

12. WANG C., WANG, F. Structural Decomposition Analysis of Carbon Emissions and Policy Recommendations for Energy Sustainability in Xinjiang. Sustainability, 7 (6), 7548, 2015.

13. WANG C., ZHANG X., WANG F., LEI J., ZHANG L. Decomposition of energy-related carbon emissions in Xinjiang and relative mitigation policy recommendations. Frontiers of Earth Science, 9 (1), 65-76, 2014.

14. GUO B., GENG Y., FRANKE B., HAO H., LIU Y.X., CHIU A. Uncovering China's transport $\mathrm{CO}_{2}$ emission patterns at the regional level. Energy Policy, 74 (74), 134, 2014.

15. XU B., LIN B. Factors affecting carbon dioxide emissions in China's transport sector: a dynamic nonparametric additive regression model. Journal of Cleaner Production, 101, 311, 2015.

16. LIN B.Q., XIE C. Reduction potential of $\mathrm{CO}_{2}$ emissions in China's transport industry. Renewable and Sustainable Energy Reviews, 33, 689, 2014.

17. YIN X., CHEN W., EOM J., CLARKE L.E., KIM S.H., PATEL P.L., YU S., KYLE G.P. China's transportation energy consumption and $\mathrm{CO}_{2}$ emissions from a global perspective. Energy Policy, 82 (1), 233, 2015.

18. YANG W., LI T., CAO X. Examining the impacts of socioeconomic factors, urban form and transportation development on $\mathrm{CO}_{2}$ emissions from transportation in China: A panel data analysis of China's provinces. Habitat International, 49, 212, 2015.

19. CAI B., YANG W., CAO D., LIU L., ZHOU Y., ZHANG, Z. Estimates of China's national and regional transport sector $\mathrm{CO}_{2}$ emissions in 2007. Energy Policy, 41, 474, 2012.

20. AL-MULALI U., FEREIDOUNI H.G. MOHAMMED A.H. The effect of tourism arrival on $\mathrm{CO}_{2}$ emissions from transportation sector. Anatolia, 26 (2), 1, 2015.

21. DAI Y., GAO H.O. Energy consumption in China's logistics industry: A decomposition analysis using the LMDI approach. Transportation Research Part D: Transport and Environment, 46, 69, 2016.

22. RATANAVARAHA V., JOMNONKWAO S. Trends in Thailand $\mathrm{CO}_{2}$ emissions in the transportation sector and Policy Mitigation. Transport Policy, 41, 136, 2015.

23. SHAHBAZM., KHRAIEF N., JEMAAM.M.B. On the causal nexus of road transport $\mathrm{CO}_{2}$ emissions and macroeconomic variables in Tunisia: Evidence from combined cointegration tests. Renewable and Sustainable Energy Reviews. 51 (16), 89, 2015.

24. NOCERA S., CAVALLARO F. A methodological framework for the economic evaluation of $\mathrm{CO}_{2}$ emissions from transport. 
Journal of Advanced Transportation, 48(2), 138, 2014.

25. AZLINAA A.A., LAW S. H., MUSTAPHA N.H.N. Dynamic linkages among transport energy consumption, income and $\mathrm{CO}_{2}$ emission in Malaysia. Energy Policy, 73, 598, 2014.

26. STELLING P. Policy instruments for reducing $\mathrm{CO}_{2}$ emissions from the Swedish freight transport sector. Research in Transportation Business and Management, 12, 47, 2014.

27. CHANDRAN V.G.R., TANG C.F. The impacts of transport energy consumption, foreign direct investment and income on $\mathrm{CO}_{2}$ emissions in ASEAN-5 economies. Renewable and Sustainable Energy Reviews, 24 (10), 445, 2013.

28. LIIMATAINEN H., PÖLLÄNEN M. The impact of sectoral economic development on the energy efficiency and $\mathrm{CO}_{2}$ emissions of road freight transport. Transport Policy, 27 (2), 150, 2013.

29. WEI Q., ZHAO S., XIAO W. A Quantitative Analysis of Carbon Emissions Reduction Ability of Transportation Structure Optimization in China. Journal of Transportation Systems Engineering and Information Technology, 13 (3), 10, 2013.

30. WANG W.W., ZHANG M., ZHOU M. Using LMDI method to analyze transport sector $\mathrm{CO}_{2}$ emissions in China. Energy, 36 (10), 5909, 2011.

31. MAO X., YANG S., LIU Q., TU J., JACCARD M. Achieving $\mathrm{CO}_{2}$ emission reduction and the co-benefits of local air pollution abatement in the transportation sector of China. Environmental Science and Policy, 21 (4), 1, 2012.

32. XU B., LIN B. Differences in regional emissions in China's transport sector: Determinants and reduction strategies. Energy, 95, 459, 2016.

33. ZHAO Y., KUANG Y., HUANG N. Decomposition Analysis in Decoupling Transport Output from Carbon Emissions in Guangdong Province, China. Energies, 9 (4), 295, 2016.

34. LIU Z., LI L., ZHANG Y.J. Investigating the $\mathrm{CO}_{2}$ emission differences among China's transport sectors and their influencing factors. Natural Hazards, 77 (2), 1323, 2015.

35. VOIGT S., DE CIAN E., SCHYMURA M., VERDOLINI E. Energy intensity developments in 40 major economies: Structural change or technology improvement? Energy Economics, 41, 47, 2014.

36. WANG Q., LI R. Drivers for energy consumption: A comparative analysis of China and India. Renewable and Sustainable Energy Reviews, 62, 954, 2016.

37. SCHOLL L., SCHIPPER L., KIANG N. $\mathrm{CO}_{2}$ emissions from passenger transport A comparison of international trends from 1973 to 1992. Energy Policy, 24 (1), 17, 1996.

38. TIMILSINA G.R., SHRESTHA A. Transport sector $\mathrm{CO}_{2}$ emissions growth in Asia: Underlying factors and policy options. Energy Policy, 37 (11), 4523, 2009.

39. WANG Q., CHEN X., JHA A.N., ROGERS H. Natural gas from shale formation-The evolution, evidences and challenges of shale gas revolution in United States. Renewable and Sustainable Energy Reviews, 30 (0), 1, 2014.

40. TIMILSINA G.R., SHRESTHA A. Factors affecting transport sector $\mathrm{CO}_{2}$ emissions growth in Latin American and Caribbean countries: An LMDI decomposition analysis. International Journal of Energy Research, 33 (4), 396, 2009.

41. SHAHBAZ M., LOGANATHAN N., MUZAFFAR A.T., AHMED K., ALI JABRAN M. How urbanization affects $\mathrm{CO} 2$ emissions in Malaysia? The application of STIRPAT model. Renewable and Sustainable Energy Reviews, 57 (5), 83, 2016.

42. MCKINNON A.C., PIECYK M.I. Measurement of $\mathrm{CO}_{2}$ emissions from road freight transport: A review of $\mathrm{UK}^{2}$ experience. Energy Policy, 37 (10), 3733, 2009.

43. ANG B.W. The LMDI approach to decomposition analysis: a practical guide. Energy Policy, 33 (7), 867, 2005.

44. XU X.Y., ANG B.W. Index decomposition analysis applied to $\mathrm{CO}_{2}$ emission studies. Ecological Economics, 93 (5), 313, 2013.

45. ANG B.W., XU X.Y. Tracking industrial energy efficiency trends using index decomposition analysis. Energy Economics, 40 (2), 1014, 2013.

46. PAPAGIANNAKI K., DIAKOULAKI D. Decomposition analysis of $\mathrm{CO}_{2}$ emissions from passenger cars: the cases of Greece and Denmark. Energy Policy, 37 (8), 3259, 2009.

47. ANDREONI V., GALMARINI S. Decoupling economic growth from carbon dioxide emissions: A decomposition analysis of Italian energy consumption. Energy, 44 (1), 682, 2012.

48. FREITAS L.C.D., KANEKO S. Decomposing the decoupling of $\mathrm{CO}_{2}$ emissions and economic growth in Brazil. Ecological Economics, 70 (8), 1459, 2011.

49. GREENING L.A., TING M., DAVIS W.B. Decomposition of aggregate carbon intensity for freight: trends from 10 OECD countries for the period 1971-1993. Energy Economics, 21 (4), 331, 1999.

50. WANG W., LIU R., ZHANG M., LI H. Decomposing the decoupling of energy-related $\mathrm{CO}_{2}$ emissions and economic growth in Jiangsu Province. Energy for Sustainable Development, 17 (1), 62, 2013.

51. LAHA S., LUTHY R.G. Decoupling Analysis and Socioeconomic Drivers of Environmental Pressure in China. Environmental science \& technology, 48 (2), 1103, 2014.

52. LU Q., YANG H., HUANG X., CHUAI X., WU, C. Multisectoral decomposition in decoupling industrial growth from carbon emissions in the developed Jiangsu Province, China. Energy, 82, 414, 2015.

53. TAPIO P. Towards a theory of decoupling: degrees of decoupling in the EU and the case of road traffic in Finland between 1970 and 2001. Transport Policy, 12 (2), 137, 2005.

54. PAUSTIAN K., RAVINDRANATH N.H., AMSTEL A.R. 2006 IPCC Guidelines for National Greenhouse Gas Inventories. 2 (4), 48, 2006.

55. SONG R.P., YANG S., SUN M. GHG Protocol Tool for Energy Consumption in China (Version 2.1), 2013; World Resources Institute: Beijing, China, 2013.

56. GU B., TAN X., ZENG Y., MU Z. $\mathrm{CO}_{2}$ Emission Reduction Potential in China's Electricity Sector: Scenario Analysis Based on LMDI Decomposition. Energy Procedia, 75, 2436, 2015.

57. LI H.Z., TIAN X.L., ZOU T. Impact analysis of coalelectricity pricing linkage scheme in China based on stochastic frontier cost function. Applied Energy, 151, 296, 2015.

58. WANG Q., CHEN X. China's electricity market-oriented reform: From an absolute to a relative monopoly. Energy Policy, 51, 143, 2012.

59. WANG Q., CHEN Y. Status and outlook of China's freecarbon electricity. Renewable and Sustainable Energy Reviews, 14 (3), 1014, 2010.

60. KAYA Y., YOKOBORI K. Environment, Energy, and Economy: Strategies for Sustainability. United Nations University Press. 1997.

61. XU X.Y., ANG B.W. Multilevel index decomposition analysis: Approaches and application. Energy Economics, 44, 375, 2014.

62. ANG B.W., XU X.Y., SU, B. Multi-country comparisons of energy performance: The index decomposition analysis 
approach. Energy Economics, 47, 68, 2015.

63. ANG B.W., CHOI K.H. Decomposition of Aggregate Energy and Gas Emission Intensities for Industry: A Refined Divisia Index Method. Energy Journal, 18 (3), 59, 1997.

64. VEHMAS J., LUUKKANEN J., KAIVO-OJA J. Linking analyses and environmental Kuznets curves for aggregated material flows in the EU. Journal of Cleaner Production, 15 (17), 1662, 2007

65. DIAKOULAKI D., MANDARAKA M. Decomposition analysis for assessing the progress in decoupling industrial growth from $\mathrm{CO}_{2}$ emissions in the EU manufacturing sector.
Energy Economics, 29 (4), 636, 2007.

66. National Bureau of Statistics of China. National Economy Industry Classification Annotations 2011, $4^{\text {th }}$ ed.; China Statistics Press: Beijing, China, 2011.

67. Department of Energy Statistics, National Bureau of Statistics, China Energy Statistical Yearbook (1990-2014); China Statistics Press: Beijing, China, 2014.

68. Statistics Bureau of Xinjiang Uygur Autonomous Region; Xinjiang Statistical Yearbook (1990-2014); China Statistics Press: Beijing, China, 2014. 